\title{
PVC Based Ion-Exchange Membrane Blended with Magnesium Oxide Nanoparticles for Desalination: Fabrication, Characterization and Performance
}

\author{
F. Parvizian*, Z. Sadeghi, S. M. Hosseini \\ Department of Chemical Engineering, Faculty of Engineering, \\ Arak University, Arak 38156-8-8349, Iran
}

\begin{abstract}
In this study, polyvinyl chloride (PVC) based nanocomposite cation exchange membranes incorporated with magnesium oxide $(\mathrm{MgO} 0$ nanoparticles were fabricated by nonsolvent induced phase inversion method. The additive concentration and electrolyte conditions (concentrations/pH) were investigated. Morphology studies were done using SOM and SEM images exhibited uniform distribution of $\mathrm{MgO}$ nanoparticles in the membrane structure. FTIR analysis showed the chemical structure of prepared membrane that demonstrated $\mathrm{MgO}$ nanoparticles presence. The hydrophilicity of membranes increased when $0.5-4.0 \mathrm{wt} . \%$ of additive were embedded into the polymer matrix. The transport characteristics of prepared membrane were improved by increasing nanoparticle content from 0.5 to $1 \mathrm{wt} . \%$. It was demonstrated that the ionic flux of developed cation exchange membranes improved with an increase in additive content up to $1 \mathrm{wt} . \%$. A considerable reduction was observed in the values of electrical resistance for the prepared membrane containing $\mathrm{MgO}$ nanoparticles. Ionic selectivity was enhanced at the more concentered solution and was slightly decreased at higher electrolyte concentration. Moreover, at the electrolyte solution of $\mathrm{pH} 7$ the optimal transport properties were achieved for the membranes.
\end{abstract}

Keywords: Desalination, ion exchange membrane, $\mathrm{MgO}$ nanoparticle, $\mathrm{PVC}$, polymer matrix

\subsection{INTRODUCTION}

Ion exchange membranes (IEMs) have numerous applications in separation processes. The most important of these processes are electro-dialysis and membrane chloralkali cells. Nowadays, IEMs have been widely used in electrodialysis process for seawater desalination and extraction of valuable metals ions from industrial wastewater, etc. [1-16].

Based on preparation procedure and structures of ion-exchange membranes, they are classified into homogeneous and heterogeneous [17]. Moreover, according to functional groups of IEMs, they are classified by anionic and cationic ones. Anion exchange membranes pass anions and repel cations, while cation exchange membranes allow the pass of cations, but reject anions [18]. Many studies have already been done on improving the physicochemical properties of IEMs. Some of the most important techniques to achieve superior ion exchange membranes include the use of different polymeric matrices, inorganic additives/fillers such as metal oxide and nanomaterials, polymers blending, surface modification, difference in functional groups' form and alteration of cross-link density. 
Using inorganic nanoparticles, especially metal oxides in the structure of polymeric membranes could improve the physicochemical and separation properties due to desirable interaction between the organic and inorganic composition [13, 1920].

With this respect, magnesium oxide $(\mathrm{MgO})$ as a unique solid with high ionic character and electrical conductivity has found novel applications in electronics, adsorption, detection and remediation of chemical waste and other research areas. Magnesium oxide nanoparticles are odorless and non-toxic. They possess high hardness, high purity and a high melting point. $\mathrm{MgO}$ nanoparticle is an important material, which used in many applications like catalysis, toxic waste remediation, paint, superconducting products and antibacterial activities against food borne pathogens.

$\mathrm{MgO}$ is an interesting basic oxide that has many applications in analysis, adsorption and in the synthesis of refractory ceramics. It is a unique solid of high ionic character. It has been reported that the shape and size of nanocrystalline magnesium oxide particles endow them with high specific surface and reactivity, because of the high concentration of edge/corner sites and structural defects on their surface $[1,2,10,19-27]$. So $\mathrm{MgO}$ nanoparticles can be considered to modify ion exchange membranes.

The aim of this research was to prepare a new heterogeneous cation exchange membrane based on the polyvinyl chloride (PVC) containing $\mathrm{MgO}$ nanoparticles by solution casting techniques which can be used in electro-dialysis process. Appropriate mechanical stability, excellent resistance to erosion, acids and alkaline, and also low cost are reasons that PVC was used for this purpose [2, 28-34]. Therefore, at the next step of the present research, the modified ion exchange membranes were applied in electrolytes with different concentration and $\mathrm{pH}$ to examine their performance under diverse conditions [35]. The variations of membrane resistance, potential and ionic selectivity were investigated in $\mathrm{NaCl}$ solution with concentration range of $0.001-0.1 \mathrm{M}$ and $\mathrm{pH}$ range of 2-12. The obtained results might have practical value in the field of water treatment using various electromembrane processes especially electro-dialysis process.

\subsection{METHODS}

\subsection{Materials}

Polyvinyl chloride (PVC, grade S7054, density: $490 \mathrm{~g} / \mathrm{L}$, viscosity number: $105 \mathrm{~cm}^{3} / \mathrm{g}$ ) was used as binder polymer obtained from Bandare Imam Petrochemical Co. (Iran). Tetrahydrofuran (THF, MW: 72.11, density: $\left.0.89 \mathrm{~g} / \mathrm{cm}^{3}\right)$ and deionized water were used as solvent and nonsolvent. The functional group agent was acidic cation exchanger resin (Amberlyst $^{\circledR} 15$, particle size of $0.355-$ $1.18 \mathrm{~mm}$, strongly acidic cation exchanger, $\mathrm{H}^{+}$form with more than 1.7 meq/L, density $0.6 \mathrm{~g} / \mathrm{cm}^{3}$ ) produced by Merck Inc. (Germany). Also $\mathrm{MgO}$ nanoparticle ( $\mathrm{MgO}$ nano-whitepowder, average particle size $20 \mathrm{~nm}$, (MW: 40.30), (density: $3.58 \mathrm{~g} / \mathrm{cm}^{3}$ ), BET area $\left.50 \mathrm{~m}^{2} / \mathrm{g}\right)$ was used as inorganic modifier. The other chemical components were supplied by Merck. 


\subsection{Fabrication of $\mathrm{PVCl} \mathrm{MgO}$ Cation Exchange Membranes}

PVC-based cation exchange membranes were fabricated by solution casting technique and phase inversion method [32, 33]. In order to dehumidify of the resin particles; they were put in oven (SANEE.V. S. Co.) at $30^{\circ} \mathrm{C}$ for $48 \mathrm{~h}$ and then were milled in a ball mill (Model: Pulverisette 5, Fritisch Co.). Then, by sieving the resin powder, the desired size (37- 44 $\mathrm{mm}$ ) was obtained for membrane fabrication. The polymer binder (PVC) was dissolved into the solvent (THF) (polymer: solvent (1: 20); (w/v)). Subsequently, a specific amount of the grinded resin particle and various percentages of $\mathrm{MgO}$ nanoparticles as additive were dispersed in the polymeric solution. Casting solution was mechanically stirred for $6 \mathrm{~h}$ to be uniform. The solutions were put in an ultrasonic bath for $1 \mathrm{~h}$ to achieve a desirable dispersion of nanoparticles and then, the mixture was stirred again using mechanical stirrer for half an hour. Afterward, the prepared solution was cast onto a glass with a knife and a gap of $400 \mu \mathrm{m}$ at ambient temperature. The membranes were exposed to air for $60 \mathrm{~s}$ to dry and then immersed into coagulation bath containing DI water. The membrane thicknesses were measured by a digital caliper and their values were obtained around $70 \mu \mathrm{m}$. The prepared membranes were kept in a solution of sodium chloride for $24 \mathrm{~h}$ before testing.

\subsection{Experimental Test Cell}

The membranes characteristics were examined by means of home-made experimental cell as shown in Figure 1.
The cell was composed of two cylindrical sections made of Pyrex. Two compartments were separated by a membrane and at the end of each section a Pt electrode was placed.

\subsection{Characterization of Cation Exchange Membrane}

\subsubsection{FTIR Analysis}

In this study, the chemical structure of membrane was investigated using FTIR system (Fourier Transform Infrared Spectroscopy, Galaxy series 5000). Samples were scanned in the range of $4000-500 \mathrm{~cm}^{-1}$.

\subsubsection{Microstructure Analysis}

The prepared membrane characteristics are depended on its structure, especially the distribution of its ionic site and dispersed nanoparticles [21]. The structure of prepared membrane was studied by SOM (scanning optical microscopy) images (Olympus, model IX 70) and SEM (scanning electron microscopy, Philips X-130) analysis.

\subsubsection{Water Content}

The difference between wet and dry weight of the membrane is defined as membrane water content $(\varnothing)$ as follows $[2-4,10]$ :

$\phi=\left(\frac{M_{w e t}-M_{d r y}}{M_{d r y}}\right) \times 100$

$\mathrm{M}_{\mathrm{wet}}$ and $\mathrm{M}_{\text {dry }}$ represent the mass of the wet and dry membrane, respectively. $M_{\text {wet }}$ was the weight of prepared membrane after immersing into the deionized water for sufficient time. After drying the membrane in 


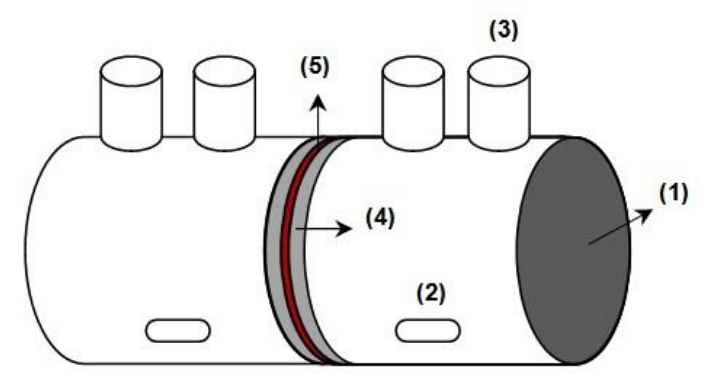

Figure 1 Schematic diagram of test cell. (1) Pt electrode, (2) Magnetic bar, (3) Orifice, (4) Rubber ring and (5) Membrane

oven at $60^{\circ} \mathrm{C}$ a constant weight was obtained as $\mathrm{M}_{\text {dry. }}$.

\subsubsection{Potential and Transport Properties of IEMs}

Differences in the concentrations of solutions in both sides of membrane develop an electrical potential which is affected by the properties of electrolyte solution.

The potential at the two sides of the membrane can be considered as the sum of Donnan potential plus diffusion potential in the membrane [20, 24]. The effect of boundary layers was eliminated by stirring both solutions using magnetic stirrers. To measure membrane potential, both sections were connected to $\mathrm{pH}$ meter electrodes and a digital auto-multimeter (Model: DEC 330FC, China) was used. The membrane potential (EMeasure) can be determined using the Nernst equation $[2-4,20]$ :

$$
E_{\text {Measure }}=\left(2 t_{i}^{m}\right)\left(\frac{R T}{n F}\right) \ln \left(\frac{a_{1}}{a_{2}}\right)
$$

In this equation, $a_{1}, a_{2}$ are the activities of solutions electrolyte in the both sides of the membrane as determined by the Debye-Huckel limiting law [36]. Also, $\mathrm{t}_{\mathrm{i}}^{\mathrm{m}}, \mathrm{R}, \mathrm{T}$ and $\mathrm{n}$ are the counter-ions' transport number in the membrane, gas constant, temperature and electrovalence of the counter-ion, respectively. The permselectivity $\left(\mathrm{P}_{\mathrm{s}}\right)$ of ion exchange membranes reflects the membrane ability to discriminate between counter- and co-ions [2, 5, 3739] This characteristic is developed based on counter-ion migration through the IEM according to [2- 4, 7, 40-44]:

$$
P_{s}=\frac{t_{i}^{m}-t_{0}}{1-t_{0}}
$$

where $t_{0}$ is the transport number of the [40].

\subsubsection{Membrane Flux and Ionic Permeability}

The flux and ionic permeability of the membranes were investigated, using the mentioned experimental cell which contains $0.01 \mathrm{M}$ sodium chloride solution in the cathodic side. A direct constant electrical potential with an optimum voltage of $10 \mathrm{~V}$ was applied throughout the cell, using two connected platinum electrodes in two parts. Thus, the ions, with a positive charge, pass through the cation exchange membrane. Also, the $\mathrm{pH}$ of cathodic section is increased due to the production of hydroxide ions in this region by electrochemical reactions.

Cathodic reaction:

$2 \mathrm{H}_{2} \mathrm{O}+2 \mathrm{e}^{-} \Rightarrow \mathrm{H}_{2}(\mathrm{~g})+2 \mathrm{OH}^{-}$

Anodic reaction:

$2 \mathrm{Cl}-\Rightarrow \mathrm{Cl}_{2}(\mathrm{~g})+2 \mathrm{e}^{-}$ 


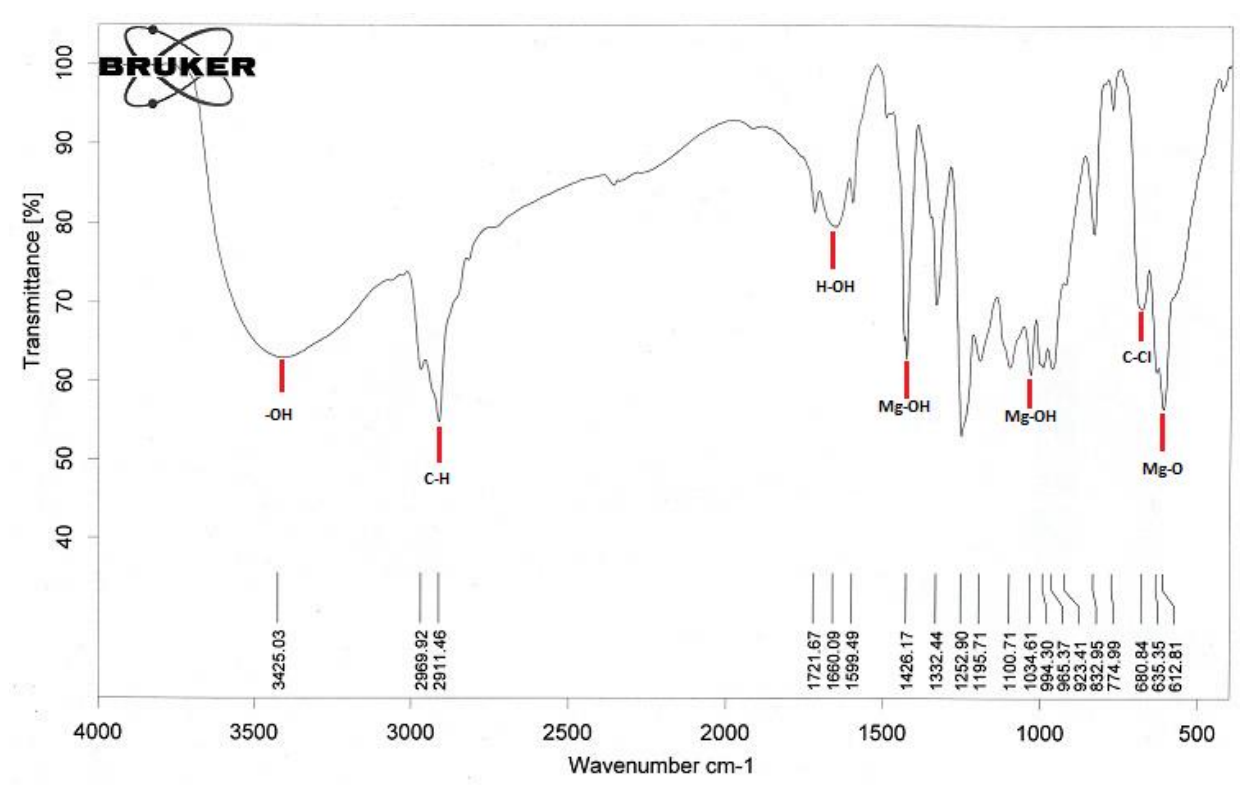

Figure 2 ATR-FTIR spectrums of PVC/Nano-MgO ion exchange membranes

The ionic flux can be determined using Fick's first law as follows [20, 21]:

$N=-\frac{V}{A} \times \frac{d C_{1}}{d t}=P \frac{C_{1}-C_{2}}{d}$

In this equation, $\mathrm{P}, \mathrm{d}, \mathrm{N}, \mathrm{C}$ and $\mathrm{A}$ are the ions diffusion coefficient, thickness of membrane, ionic flux, concentration of cations and the membrane surface area, respectively.

Eq. (4) integration is as follows:

$\ln \frac{\left(C_{1}^{0}+C_{2}^{0}-2 C_{2}\right)}{\left(C_{1}^{0}-C_{2}^{0}\right)}=-\frac{2 P A t}{V d}$

Regarding the $\mathrm{pH}$ changes in cathodic side, the diffusion coefficient of ions can be determined by Eq. (5).

\subsubsection{Electrical Resistance}

Measuring the membrane resistance is important in the evaluation of various functional groups contributions in the ion exchange task, and also it plays a vital role in the practical application of ion exchange membranes. The membrane electrical resistance was calculated, based on our previous works, using a test cell [2-4]. Electrical resistance was measured in sodium chloride solution with the concentration of $0.5 \mathrm{M}$ at $25^{\circ} \mathrm{C}$, using $1000 \mathrm{~Hz}$ AC. The difference between the resistance of the cell $\left(\mathrm{R}_{1}\right)$ with the membrane and without the membrane $\left(R_{2}\right)$ that $\left(R_{m}=R_{1}-R_{2}\right)$ is the electrical resistance of membrane [1, 24, 45-48].

Areal resistance ( $r$ ) is obtained by multiplying $\mathrm{R}_{\mathrm{m}}$ in the area of membrane surface (A) as follows:

$$
\mathrm{r}=\left(\mathrm{R}_{\mathrm{m}} \mathrm{A}\right)
$$

\subsection{RESULTS AND DISCUSSION}

\subsection{Fourier Transform Infrared Spectroscopy (FTIR)}

FTIR spectrum of prepared $\mathrm{PVC} /$ Nano-MgO ion exchange membrane is shown in Figure 2. The peak at 635 $\mathrm{cm}^{-1}$ is related to the $\mathrm{Mg}-\mathrm{O}$ bonding [49]. Due to the interaction between $\mathrm{MgO}$ and presence moisture, absorption peaks at $1426 \mathrm{~cm}^{-1}$ and $1034 \mathrm{~cm}^{-1}$ were observed that show the $\mathrm{Mg}-\mathrm{OH}$ stretching vibration. 


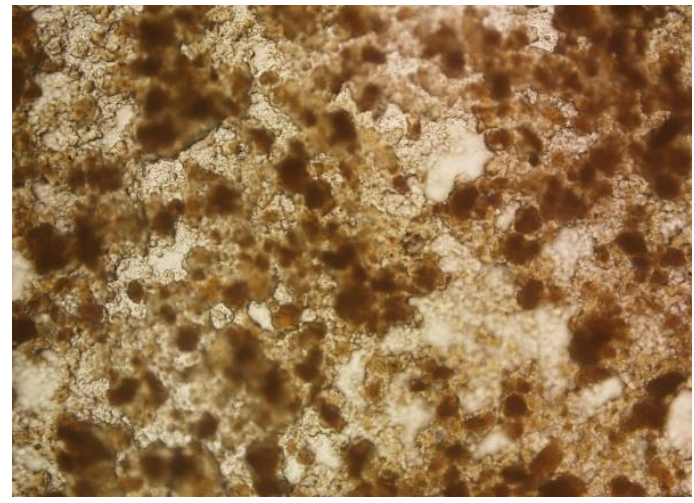

(a)

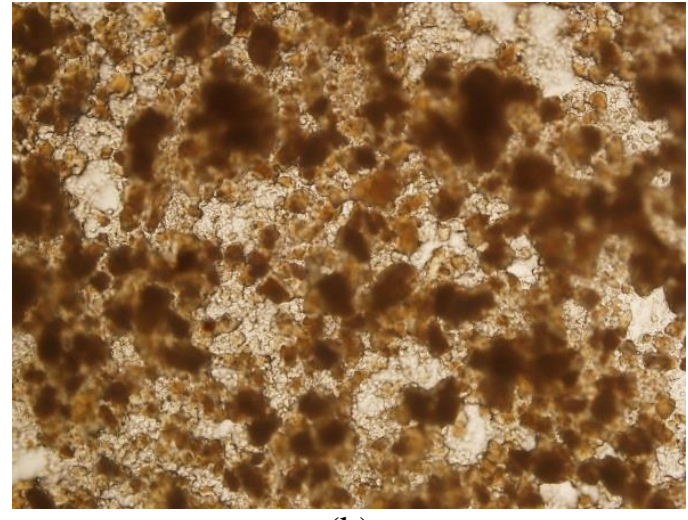

(b)

Figure 3 The SOM images (10x magnifications) of home-made membranes with different concentration of $\mathrm{MgO}$ nanoparticle: (a) $0.0 \mathrm{wt} \%$ and (b) $4 \mathrm{wt} \%$

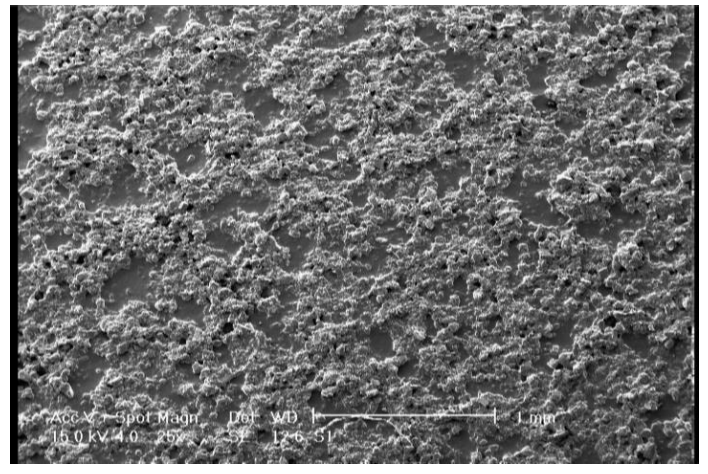

(a) $25 x$

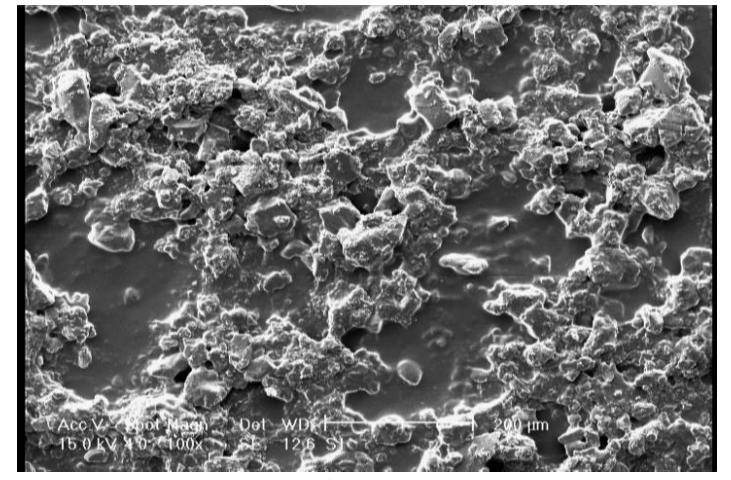

(b) $100 x$

Figure 4 SEM images of prepared membranes

Absorption peak for $\mathrm{C}-\mathrm{H}$ stretching was observed at $2911 \mathrm{~cm}^{-1}$. Also the peak at $680 \mathrm{~cm}^{-1}$ corresponds to $\mathrm{C}-\mathrm{Cl}$ functional group of PVC [50]. The broad peak at $3425 \mathrm{~cm}^{-1}$ was demonstrated to the present of $\mathrm{OH}$ functional group [51] of PVA structure. Whereas water has been used during membrane preparation an absorption peak was appeared at 1660 $\mathrm{cm}^{-1}$ [49].

\subsection{Microstructure Analysis}

To study the morphological changes associated with the additive and ionic site condition, SOM images of the prepared membranes surface were taken as shown in Figure 3. As shown in these figures with increasing the additive, the image brightness was decreased. Also SEM images at $25 \mathrm{x}$ and 100x magnifications of surfaces of prepared membrane are shown in Figure 4.

In general, uniformed distribution of nanoparticles on the membrane surface was observed that has been affected by sonication. The uniformed dispersion of particles creates regions with higher conductivity that facilitates counter ion transportation.

\subsection{Water Content}

Figure 5 shows the measured quantities of water contained in the prepared membranes. By an increase in 
nanoparticles concentration up to 0.5 $\mathrm{wt} \%$, the water content of membrane decreased. This is due to the pores filling by the magnesium oxide nanoparticle in this loading ratio.

However, with the more adding of nanoparticles in the range of 0.5 to 4 wt $\%$, the membrane water content increased. This can be observed that hydrophilicity affinity of $\mathrm{MgO}$ nanoparticles to the water make more hydrophilic membrane.

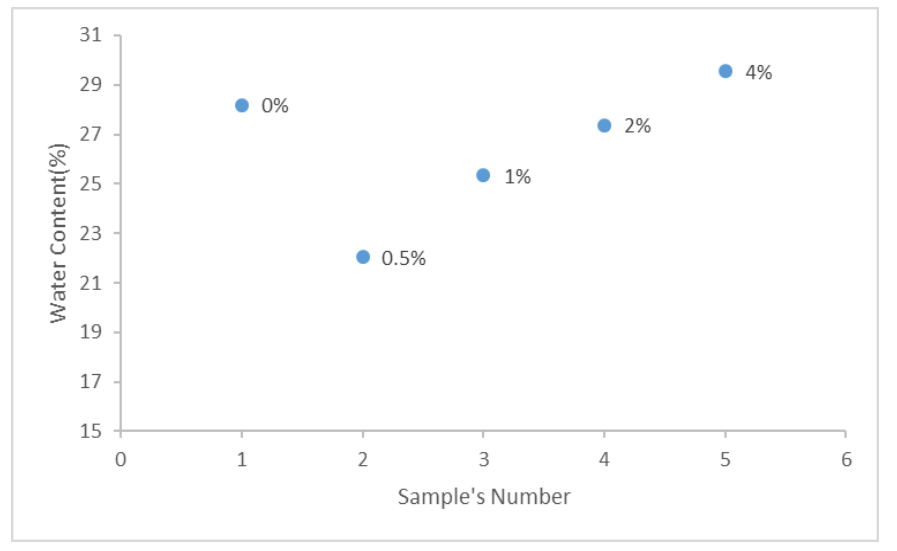

Figure 5 The effect of $\mathrm{MgO}$ nanoparticle loading on membrane water content

The appropriate quantity of water content, leads to a better control over the ions pathways and so enhances the selectivity of membrane [43]. While the large amounts of water content causes to loose the membrane structure.

\subsection{Potential and Transport Properties of IEMs}

In Figure 6 (a) and (b), the potential, transport number and permselectivity of the fabricated membranes are presented. Results indicate the membranes' properties are dependent on $\mathrm{MgO}$ nanoparticle concentration. By adding nano- $\mathrm{MgO}$ up to $0.5 \mathrm{wt} \%$, the membrane potential decreases. This is because of nanoparticles' agglomeration and so decreasing the active sites effective surface areas and reducing the adsorption properties of membranes. However, the membrane potential increased with increasing $\mathrm{MgO}$ concentration from 0.5 to $1 \mathrm{wt} \%$. The reason is that nanoparticles provide more conducting areas and create suitable flow channels throughout the membranes which facilitate the counter-ions passage. Thus, the Donnan exclusion responsible for the membrane potential increment is enhanced [4, 19, 39-42].

The transport properties of membrane declined by adding the nanoparticles more from 1 to $4 \mathrm{wt} \%$. This can be due to increase in particle density that cause reduces the effect of active sites.

Figure 6 (b) illustrates that the increase of $\mathrm{MgO}$ nanoparticles percentage (up to 0.5 wt.\%) in casting solution is associated with the reduction of transport number and permselectivity. It happened because of the accumulation of nanoparticles that led to decline in charge density of the membrane and affected the cation percolation.

Increasing the nanoparticles in the range of 0.5 to $1 \mathrm{wt}$. $\%$ led to the improvement of transport properties of membranes. It may be due to the adsorptive ability of $\mathrm{MgO}$ nanoparticle which facilitates the ion transfer. Also, 
adding the nanoparticle causes the occupation of the ionic pathways and so the ion passage becomes narrow in the membrane structure. Therefore, the ions transportation is intensified and the permselectivity of membrane is improved. However, with further increase in nanoparticles concentration from 1 to 4 wt.\%, the selectivity of membranes is declined. This declining could be as a result of the existence of higher density of nanoparticle in the polymeric solution that causes the discontinuity of polymer chain binder.

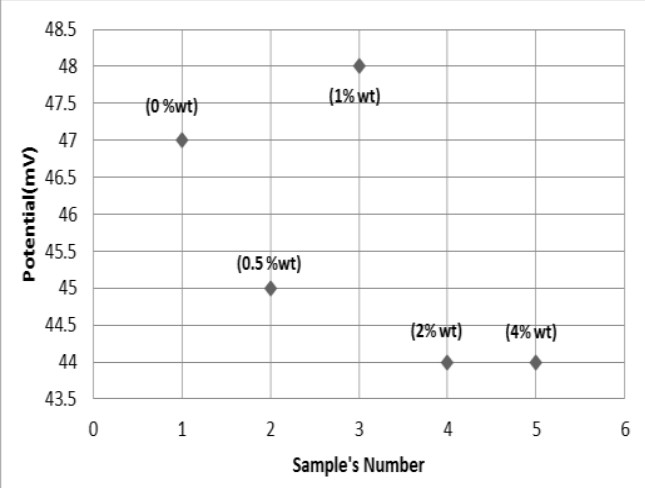

(a)

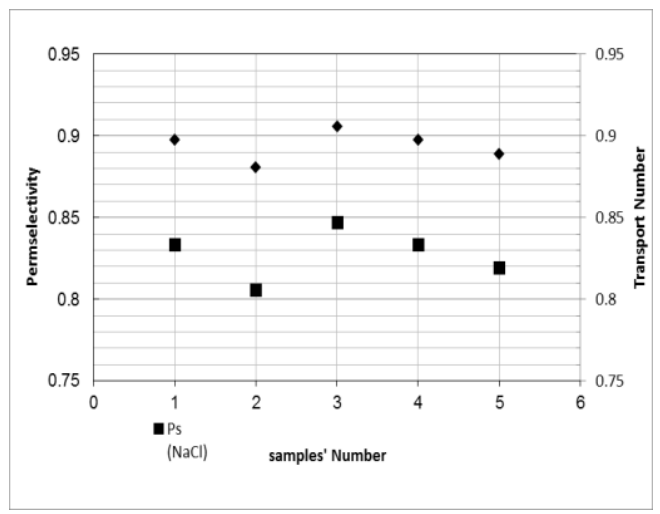

(b)

Figure 6 The potential, transport number and permselectivity of prepared membranes with various additive loading

\subsection{Membrane Flux and Ionic Permeability}

According to the amount of hydroxide ions produced at the cathodic side, the transfer of sodium ions occurs. As shown in Figure 7, with the increasing of $\mathrm{MgO}$ nanoparticles up to $1 \mathrm{wt} . \%$, the flux and ionic permeability of the membranes were enhanced.

The possible cause of this event is the improved interaction between the counter ions and the membrane surface, which is caused by the adsorption capability of $\mathrm{MgO}$ nanoparticles and facilitated ion transportation. Moreover, the surface of volume ratios of $\mathrm{MgO}$ nanoparticles is relatively high that aid to the ion diffusion from solution to particle surface. The ionic permeability and flux declined by increasing the concentration of nanoparticle from 1 to 4 wt.\%. This may be due to the pore filling phenomenon by nanoparticles which causes ion transition to be more difficult $[38,40]$.

\subsection{Electrical Resistance}

Figure 8 illustrates that the adding $\mathrm{MgO}$ nanoparticles led to reduce the areal electrical resistance of ion exchange membrane. It can be influenced by the adsorption properties of nanoparticles which assist the ion transport between the electrolyte and membrane, thereby the membrane conductivity improves. 


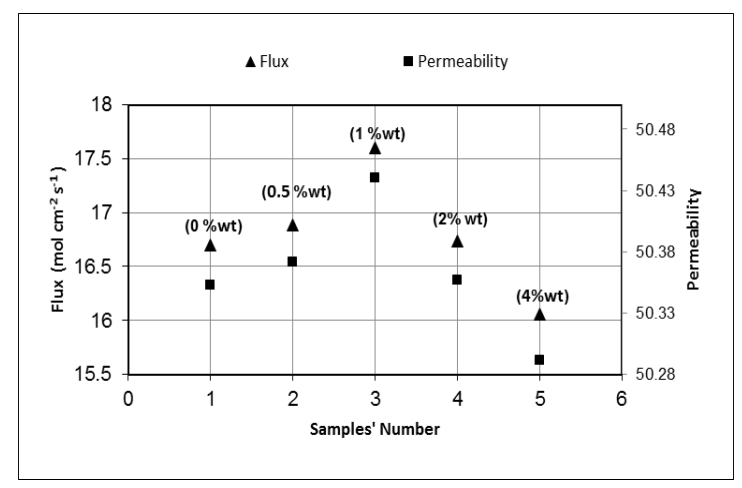

Figure 7 The effect $\mathrm{MgO}$ nanoparticles concentration on the ionic flux and permeability of sodium ions for the home-made cation exchange membranes

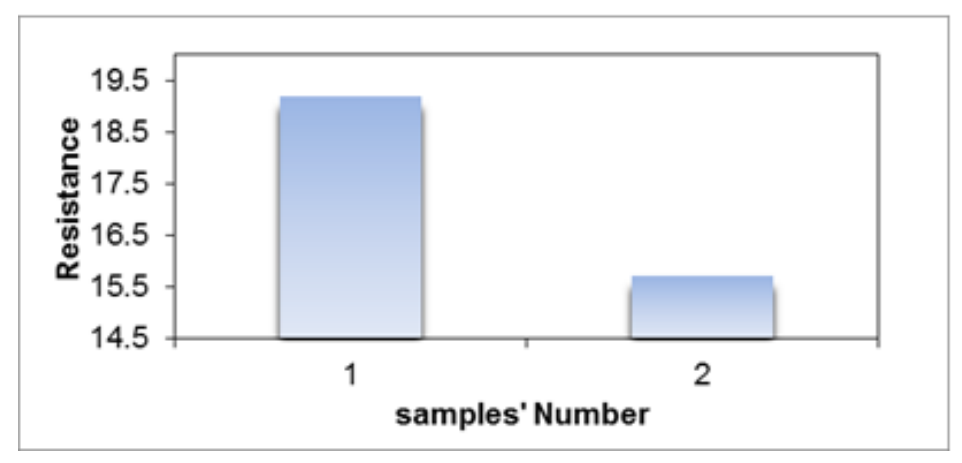

Figure 8 The areal electrical resistance of prepared membranes with various zinc oxide nanoparticle concentrations

\subsection{Effect of pH and Concentration}

Figures. 9 (a)-(c) indicate an increase in concentration of solution from (0.001-0.01) to $(0.01-0.1)$, and the transport properties of membranes were initially improved. It is due to more presence of counter-ions in the electrolyte environment which causes more interaction between counter-ions and membrane surface [24]. Therefore, Donnan exclusion is enhanced as responsible for the improvement of membrane potential and selectivity. A considerable contrast exists between the obtained results and Donnan equilibrium theory [40].

A slight decrease in all of the mentioned parameters will take place with higher increase in ionic solution concentration from $(0.01-0.1)$ to $(0.05-$ $0.5)$. The reason is the more osmotic pressure difference between the external and internal salt solution in the membrane phase at high solution concentration [39]. Besides, at high concentration of sodium chloride solution the membrane swelling may decline the transport properties of membranes [40-44].

As shown in Figures 10 (a)-(c), the modified membrane showed better performance at $\mathrm{pH} 7$ in comparison with other $\mathrm{pH}$ values. One possible explanation for happening this event could be the difference in dissociation of ionic functional groups $\left(-\mathrm{SO}_{3} \mathrm{H}\right)$ and charge density of filler additives in various $\mathrm{pH}$ values which influences the charge nature of membrane matrix [40]. In a suitable electrolyte $\mathrm{pH}$, more dissociation of sulfonic groups and higher charge nature of membrane matrix will facilitate ion transportation from solution to membrane. 


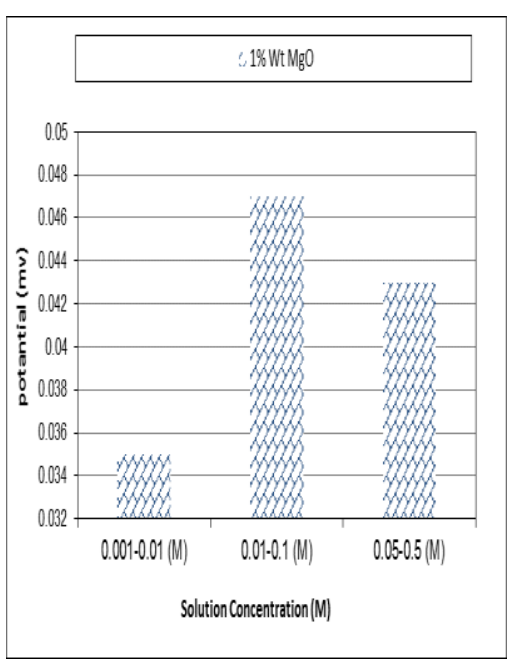

(a)

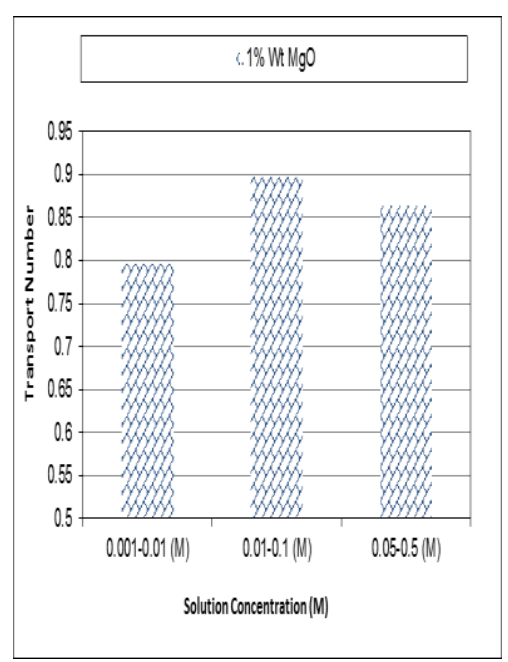

(b)

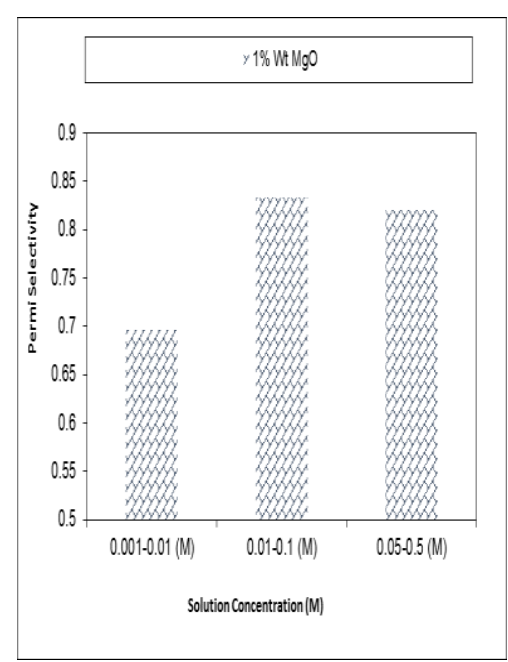

(c)

Figure 9 The effect of solution $(\mathrm{NaCl})$ concentration variations on (a) membrane potential, (b) transport number and (c) permselectivity

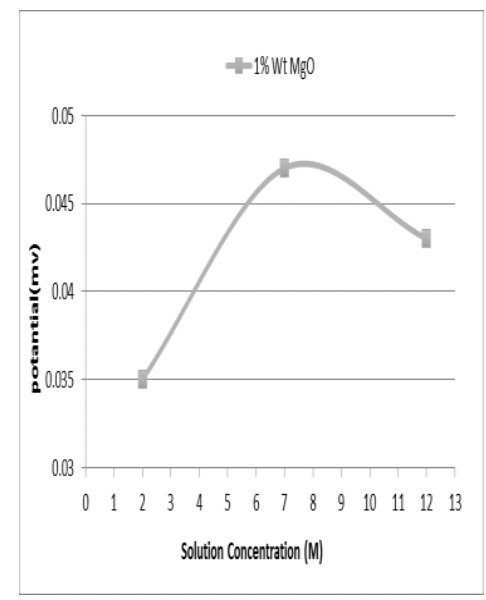

(a)

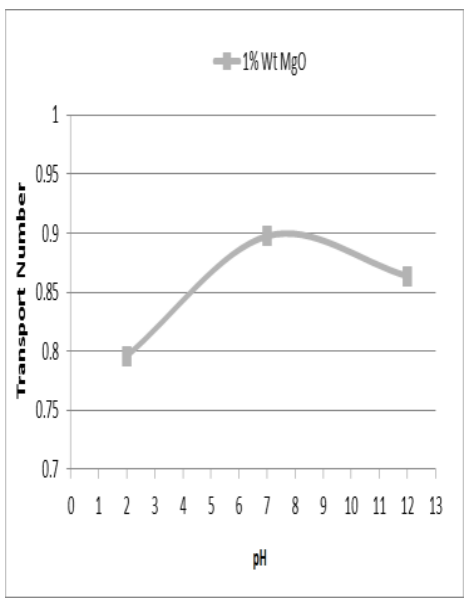

(b)

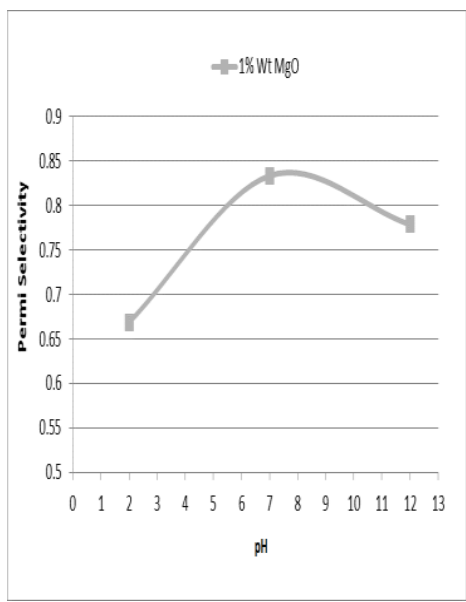

(c)

Figure 10 The effect of $\mathrm{pH}$ variations on (a) membrane potential, (b) transport number and (c) permselectivity

\subsection{CONCLUSION}

SOM images and SEM analysis showed the morphology of membranes and distribution of particles on the membrane surface. FTIR analysis demonstrated the presence of $\mathrm{MgO}$ nanoparticls in the structure of prepared membrane.
Results illustrated an initial decrease in water content of membranes by increasing the additive up to $0.5 \mathrm{wt} \%$ and then increased by more additive content. A declining trend was achieved for transport properties of membranes by adding nanoparticle up to 0.5 wt. $\%$. After that by a more additive content from 0.5 to 1 wt. $\%$, the membranes' properties enhanced. 
As the $\mathrm{MgO}$ nanoparticles increased to 4 wt.\%, the modified membranes presents the lower potential, transport number and selectivity. By adding nanoparticles up to 1 wt. $\%$, the prepared membrane exhibit a higher ionic permeability and flux and then were decreased by more increasing in additive content to $4 \%$. The electrical resistance of fabricated membrane containing nanoparticles decreased. Investigation of modified membranes performance in different electrolytic environments exhibited that by increasing electrolyte concentration. The transport properties of IEMs were enhanced and then declined slightly at high solution concentration. Also at $\mathrm{pH}$ 7 the optimized values of membranes characteristics were achieved.

\section{REFERENCES}

[1] K. Nath. 2008. Membrane Separation Processes. Prentice Hall of India Private Limited. GH Patel College of Engineering and Technology Eastern Economy Edition.

[2] R. W. Baker. 2004. Membrane Technology and Application. 2nd Ed. John Wiley \& Sons, Ltd, Membrane Technology and Research, Inc. Menlo Park, California Chichester.

[3] T. Sata, W. Yang. 2002. Studies on Cation-exchange Membranes Having Permselectivity Between Cations in Electrodialysis. $J$. Membr. Sci. 206: 31-60.

[4] M. Mulder. 1996. Basic Principles of Membrane Technology. Springer Netherlands.

[5] E. Volodina, N. Pismenskaya, V. Nikonenko, C. Larchet, G. Pourcelly. 2005. Ion Transfer Across Ion-exchange Membranes with Homogeneous and
Heterogeneous Surface. $J$. Colloid Interface Sci. 285: $247-$ 258.

[6] R. K. Nagarale, G. S. Gohil, Vinod K. Shahi, R. Rangarajan. 2004. Preparation and Electrochemical

Characterizations of Cationexchangemembranes with Different Functional Group. Physicochem. Eng. Aspects. 251: 133-140.

[7] R. K. Nagarale, G. S. Gohil, V. K. Shahi, G. S. Trivedi, R. Rangarajan. 2004. Preparation and Electrochemical Characterization of Cation and Anion-exchange/Polyaniline Composite Membranes. $J$. Colloid Interface Sci. 277 :162171.

[8] J. P. G. Villaluenga, V. M. Barragan, M. A. Izquierdo-Gil, M. P. Godino, B. Seoane, C. Ruiz-Bauza. 2008. Comparative Study of Liquid Uptake and Permeation Characteristics of Sulfonated Cation-exchange Membranes in Water and Methanol. J. Membr. Sci. 323: 421-427.

[9] M. Y. Kariduraganavar, R. K. Nagarale, A. A. Kittur, S. S. Kulkarni. 2006. Ion-exchange Membranes: Preparative Methods for Electro-dialysis and Fuel Cell Application. Desalination. 197: 225-246.

[10] P. V. Vyas, P. Ray, S. K. Adhikary, B. G. Shah, R. Rangarajan. 2003. Studies of the Effect of Variation of Blend Ratio on Permselectivity and Heterogeneity of Ion-exchange Membrane. J. Colloid Interface Sci. 257: 127-134.

[11] V. K. Shahi, S. K. Thampy, R. Rangarajan. 1999. Studies on Transport Properties of Surfactant Immobilized Anion- 
exchange Membrane. J. Membr. Sci. 158: 77-83.

[12] E. Volodina, N. Pismenskaya, V. Nikonenko, C. Larchet, G. Pourcelly. 2005. Ion Transfer Across Ion-exchange Membranes with Homogeneous and Heterogeneous Surfaces. $J$. Colloid Interface Sci. 285 : 247258.

[13] R. K. Nagarale, V. K. Shahi, R. Schubert, R. Rangarajan, R. Mehnert. 2004. Development of Urethane Acrylate Composite Ion-exchange Membranes and Their Electrochemical Characterization. J. Colloid Interface Sci. 270 : 446-454.

[14] S. Caprarescu, V. Purcar, D. I. Vaireanu. 2012. Separation of Copper Ions from Synthetically Prepared Electroplating Wastewater at Different Operating Conditions using Electrodialysis. Sep. Sci. Technol. 47(16): 2273-2280.

[15] C. O. M, Bareck, Q. T. Nguyen, S. Alexandre, I. Zimmerlin. 2006. Fabrication of Ion-exchange Ultrafiltration Membranes for Water Treatment I. Semiinterpenetrating Polymer Networks of Polysulfone And Poly (Acrylic Acid). J. Membr. Sci. 278: 10-18.

[16] T. Xu. 2005. Ion Exchange Membrane: State of Their Development and Perspective. $J$. Membr. Sci. 263 : 1-29.

[17] A. Elattar, A. Elmidaoui, N. Pismenskaia, C. Gavach, G. Pourcelly. 1998. Comparison of Transport Properties of Monovalent Anions Through Anion-exchange Membranes. $J$. Membr. Sci. 143: 249-261.

[18] J. Schauer, L. Brozova. 2005. Heterogeneous Ion-exchange Membranes Based on Sulfonated Poly (1, 4-phenylene sulfide) and
Linear Polyethylene: Preparation, Oxidation Stability, Methanol Permeability and Electrochemical Properties. J. Membr. Sci. 250: 151-157.

[19] S. Koter, A. Warszawski. 2000. Electro-membrane Processes in Environment Protection. Pol. J. Environ. Stud. 9/1: 45-56.

[20] M. R. Bindhu, M. Umadevi, M. Kavin Micheal, M. V. Arasu, N. A. Al-Dhabi. 2016. Structural, Morphological and Optical Properties of Mgo Nanoparticles for Antibacterial Applications. $J$. Materials Letters. 166: 19-22.

[21] K. Zhang, Yi an, Le. Zhang, Qi Dong. 2012. Preparation of Controlled Nano-MgO and Investigation of Its Bactericidal Properties. J. Homepage. Chemosphere. 89: 1414-1418.

[22] M. A. Alavi, A. Morsali. 2010. Syntheses and Characterization of $\mathrm{Mg}(\mathrm{OH})_{2}$ and $\mathrm{MgO}$ Nanostructures by Ultrasonic Method. Ultrasonics Sonochemistry. 17: 441-446.

[23] R. Awad. 2008. Study of the Influence of $\mathrm{MgO}$ Nano-Oxide Addition on the Electrical and Mechanical Properties of (Cu0.25T10.75)-1234

Superconducting Phase. $J$ Supercond Nov Magn. 21: 461466.

[24] Le. Huang, D. Li, Y. Lin, M. Wei, D. Evans, X. Duan. 2005. Controllable Preparation of Nano-MgO and Investigation of Its Bactericidal Propertie. Journal of Inorganic Biochemistry. 99: 986-993.

[25] T. Sata. 2004. Ion Exchange Membranes: Preparation, Characterization, Modification and Application. The Royal Society of Chemistry, Cambridge, United Kingdom.

[26] P. V. Vyas, B. G. Shah, G. S. 
Trivedi, P. Ray, S. K. Adhikary, R. Rangarajan. 2001. Characterization of Heterogeneous Anion-exchange Membrane. J. Membr. Sci. 187: 39-46.

[27] Y. Tanaka. 2007. Ion Exchange Membranes: Fundamentals and Applications Membrane Science and Technology Series. Elsevier, Netherlands. 12.

[28] R. K. Nagarale, G. S. Gohil, V. K. Shahi. 2006. Recent Developments on Ion-exchange Membranes and ElectroMembrane Processes. $A d v$. Colloid Interface Sci. 119: 97130.

[29] X. Li, Z. Wang, H. Lu, C. Zhao, H. Na, C. Zhao. 2005. Electrochemical Properties of Sulfonated PEEK used for Ion Exchange Membranes. J. Membr. Sci. 254: 147-155.

[30] J. Kerres, W. Cui, R. Disson, W. Neubrand. 1998. Development and Characterization of Crosslinked Ionomer Membranes based Upon Sulfinated and Sulfonated PSU Crosslinked PSU Blend Membranes by Disproportionation of Sulfinic Acid Groups. J. Membr. Sci. 139: 211-225.

[31] S. M. Hosseini, S. S. Madaeni, A. R. Khodabakhshi. 2010. Preparation and Surface Modification of PVC/SBR Heterogeneous Cation Exchange Membrane with Silver Nanoparticles by Plasma Treatment. J. Membr. Sci. 365: 438-446.

[32] S. M. Hosseini, S. S. Madaeni, A. R. Khodabakhshi. 2010. Preparation and Characterization of PC/SBR Heterogeneous Cation Exchange Membrane Filled with Carbon Nano-tubes. $J$. Membr. Sci. 362: 550-559.
[33] S. M. Hosseini, S. S. Madaeni, A. R. Khodabakhshi. 2010. Heterogeneous Cation Exchange Membrane: Preparation, Characterization and Comparison of Transport Properties of Mono and Bivalent Cations. Sep. Sci. Technol. 45: 2308-2321.

[34] J. Balster, O. Krupenko, I. Punt, D. F. Stamatialis, M. Wessling. 2005. Preparation and Characterization of Monovalent Ion Selective Cation Exchange Membranes Based on Sulphonated Poly (Ether Ether Keton ). J. Membr. Sci. 263: 137145.

[35] R. K. Nagarale, G. S. Gohil, V. K. Shahi, R. Rangarajan. 2004. Preparation and Electrochemical Characterization of Cationexchange Membranes with Different Functional Groups. Colloids Surf. A 251: 133-140.

[36] E. S. Wiks. 2001. Industrial Polymers Handbook: Products, Processes, Application. Wileyvch Press, Germany.

[37] J. E. MARK. 1999. Polymer Data Handbook. New York: Oxford University Press, Inc.

[38] C. A. Harper. 1975. Handbook of Plastic and Elastomers. New York: McGraw-Hill.

[39] S. M. Hosseini, S. S. Madaeni, A. R. Heidari, A. Amirimehr. 2012. Preparation and Characterization of Ion-selective Polyvinyl Chloride based Heterogeneous Cation Exchange Membrane Modified by Magnetic Ironnickel Oxide Nanoparticles. Desalination. 284: 191-199.

[40] S. M. Hosseini, S. S. Madaeni, A. R. Khodabakhshi. 2010. Preparation and Characterization of ABS/HIPS Heterogeneous Anion Exchange Membrane Filled with Activated Carbon. $J$. Appl. Polym. Sci. 118: 3371- 
3383.

[41] H. Zhang, H. X. Li, H. M. Cheng. 2006. Water-soluble Multiwalled Carbon Nanotubes Functionalized with Sulfonated Polyaniline. J. Phys. Chem. B. 110: 9095-9099.

[42] F. Parvizian, S. M. Hosseini, A. R. Hamidi, S. S. Madaeni, A. R. Moghadassi. 2014. Electrochemical Haracterization of Mixed Matrix Nanocomposite Ion Exchange Membrane Modified by $\mathrm{ZnO}$ Nanoparticles at Different Electrolyte Conditions - $\mathrm{pH} /$ concentration. Chemical Engineers. 45: 28782887.

[43] S. M. Hosseini, A. R. Hamidi, A. R. Moghadassi, F. Parvizian, and S. S. Madaeni. 2015. Preparation and Electrochemical Characterization of Polyvinylchloride/ $\mathrm{FeTiO}_{3}-\mathrm{Co}-$ Fe3O4 Nanoparticles Mixed Matrix Ion Exchange Membranes: Investigation of Concentration and $\mathrm{pH}$ Effects. $J$. Chem. Eng. 32(9): 1827-1834.

[44] G. C. Marjanovic. 2013. Recent Advances in Polyaniline Research: Polymerization Mechanism, Structural Aspects, Properties and Applications. Synth. Met. 177: 1-47.

[45] S. Zhao, Z. Wang, X. Wei, B. Zhao, J. Wang, S. Yang, S. Wang. 2011. Performance Improvement of Polysulfone Ultrafiltration Membrane using
PANiEB as Both Pore Forming Agent and Hydrophilic Modifier. J. Membr. Sci. 385-386: 251262.

[46] D. J. Guo, H. Li. 2005. Welldispersed Multi-walled Carbon Nanotube Polyaniline Composite Films. J Solid State Electrochem. 9: 445-449.

[47] C. S. S. Sangeeth, P. Jimenez, A. M. Benito, W. K. Maser, R. Menon. 2010. Charge Transport Properties of Water Dispersible Multiwall Carbon NanotubePolyaniline Composites. J. Appl. Phys. 107: 103719/1-19.

[48] Le. Huang, D. Li, Y. Lin, M. Wei, D. Evans, X. Duan. 2005. Controllable Preparation of Nano-MgO and Investigation of Its Bactericidal Propertie. Journal of Inorganic Biochemistry. 99: 986-993.

[49] J. Wu, H. Yan, X. Zhang, L. Wei, X. Liu, B. Xu. 2008. Magnesium Hydroxide Nanoparticles Synthesized in Water-in-Oil Microemulsions. J. Colloid Interface Sci. 324: 167-171.

[50] A. Bandyopadhyay, M. Sarkar, A. Bhowmick. 2006. Structureproperty Relationship in Sol-gel Derived Polymer/Silica Hybrid Nanocomposites Prepared at Various pH. J. Materials Sci. 41(18): 5981-5993.

[51] M. Foster, M. Furse, D. Passno. 2002. An FTIR Study of Water Thin Films on Magnesium Oxide. Surface Sci. 502-503: 102-108. 